Anke Assmann*, Svetlana Edygarova, Doreen Georgi, Timo Klein and Philipp Weisser

\title{
Case stacking below the surface: On the possessor case alternation in Udmurt
}

\begin{abstract}
In this paper we investigate the case split on the possessor in Udmurt. Traditionally, the choice between ablative and genitive possessor case is said to be driven by the grammatical function (GF) of the XP containing the possessor. We argue that the case split is not driven by GFs; rather, it is determined by the case value of the XP that contains the possessor. Importantly, there is no evidence which points to a possessor raising analysis in Udmurt. Instead, we present an analysis according to which the possessor always bears genitive but may be assigned another structural case by an external head. Due to a morphological constraint, stacked case features fuse into a single feature set in the postsyntactic morphological component. If accusative and genitive stack on the possessor, only the default semantic case marker, i.e., the ablative marker, can realize the resulting feature set. In any other context the genitive marker is chosen. We thus claim that there is no abstract ablative on the possessor; instead, the morphological ablative marker realizes a combination of two abstract structural cases.
\end{abstract}

Keywords: case stacking, case split, possessor raising, abstract vs. morphological case, Uralic languages

\section{Introduction}

In Udmurt, a Uralic language spoken in the Udmurt Republic in Russia, possession can be expressed in a number of ways (see Edygarova 2009 for an overview).

*Corresponding author: Anke Assmann: University of Leipzig.

E-mail: anke.assmann@uni-leipzig.de

Svetlana Edygarova: University of Helsinki. E-mail: jedygaro@mappi.helsinki.fi

Doreen Georgi: University of Leipzig. E-mail: georgi@uni-leipzig.de

Timo Klein: University of Leipzig. E-mail: timo.klein@uni-leipzig.de

Philipp Weisser: University of Leipzig. E-mail: philipp.weisser@uni-leipzig.de 
The primary possessive construction, which is the focus of this paper, has the following properties: (i) The possessor precedes the possessum, (ii) the possessor bears a case suffix, and (iii) the possessum agrees in person and number with the possessor, indicated by a suffix on the possessum (cf. (1)). The interesting fact about this construction is that the case of the possessor varies between genitive and ablative, that is, Udmurt exhibits a case split on the possessor. The possessor cases are in complementary distribution. According to the literature, the grammatical function (GF) of the possessum determines which case value the possessor bears: genitive is the default possessor case; ablative occurs if the DP containing the possessor functions as a direct object (Csúcs 1988; Vilkuna 1997; Kel'makov and Hännikäinen 1999; Winkler 2001; Nikolaeva 2002; KoptjevskajaTamm 2003; Edygarova 2009). In example (1a) the DP that contains the possessor is the subject of the verb ugnï 'to dress' and the possessor can thus only bear genitive; in (1b), however, the DP that contains the possessor serves as the direct object of the transitive verb ažžynï 'to see' and the possessor must bear ablative.

\section{(1) Possessor cases in Udmurt: ${ }^{1}$}

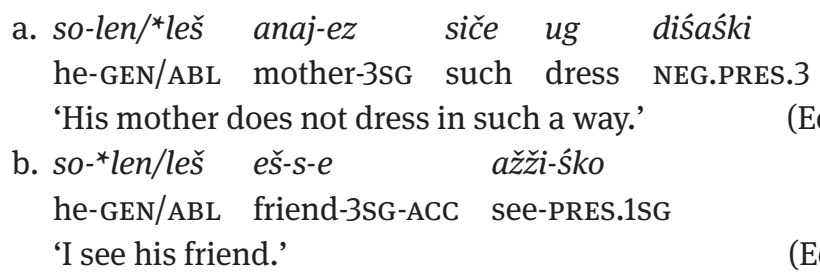

(Edygarova 2009: 105)

(Edygarova 2009: 101)

This case split is interesting for a number of reasons. First, the nature of the cases involved in the split appears to be quite unusual. The ablative case is usually not known to express possessive relations, neither cross-linguistically nor within the Uralic language family. Second, even though this split may look like an instance of possessor raising at first sight, we show that there is no reason to believe that ablative and genitive possessors occupy different structural positions. Furthermore, in many languages that exhibit a case split on possessors, it is the ob-

\footnotetext{
1 Unless references are provided, the Udmurt data in this paper are due to Svetlana Edygarova, a native speaker of Udmurt. The following abbreviations are used: 1, 2, 3 - person; ABL - ablative; ABS - absolutive; ACC - accusative; ALL - allative; AUG - augmentative; AUX - auxiliary; DAT dative; DEM - demonstrative; DIR - direct; ELA - elative; FUT - future; GEN - genitive; IMP imperative; INES - inessive; INSTR - instrumental; LIG - ligative; LOC - locative; NEG - negation; NOM - nominative; OBL - oblique; PARTC - participle; PL - plural; POSS - possessive; PRES present; PROP - proprietive; PST - past; SG - singular.
} 
ject case that alternates with the possessive case. In Udmurt, however, not the ablative, but the accusative, is the standard object case. Thus, a possessor raising analysis seems to be unmotivated for Udmurt. What we propose instead is a case stacking analysis according to which a DP in Udmurt can receive up to two structural cases in the syntax. Possessor DPs are always assigned genitive, but may receive another structural case in addition. Morphologically, however, there is only one case slot. Hence, if case stacking takes place in the syntax, fusion of the two case features into a single case feature set has to apply in the postsyntactic morphological component. The combination of genitive and accusative on the possessor yields the abstract representation of a semantic case, which is realized by the ablative exponent because it is the default semantic case marker in Udmurt. We thus claim that the possessor never actually bears abstract ablative case in Udmurt. The postsyntactic manipulation of abstract case features results in the illusion that two different abstract cases (genitive or ablative) can be assigned to the possessor, although ablative is never assigned to it in the syntax. The analysis is corroborated by the fact that the pattern observed in Udmurt fits nicely into a typology of case stacking phenomena in the world's languages.

Finally, our analysis also solves an apparent problem of cyclicity: Given a strictly derivational model of syntax in which the structure unfolds in a bottomup fashion (cf. Chomsky 1995 et seq.), the relevant information about the GF of the DP containing the possessor is not available at the point of case assignment to the possessor within the DP. The decision whether to assign abstract genitive or ablative to the possessor thus seems to require look-ahead. In our analysis, this is not necessary since case assignment proceeds as usual. The decision whether the ablative case marker occurs on the possessor is made in the postsyntactic component. The distinction between abstract and morphological case (cf. Legate 2008) is thus crucial for the analysis.

The paper is structured as follows: In Section 2, the exact distribution of the ablative and genitive possessors is determined. Furthermore, other occurrences of ablative case are investigated in order to find an answer to the question why the alternative possessor case is the ablative. Section 3 presents the analysis that derives the empirical generalizations gained from the preceding section. Afterwards, in Section 4, some theoretical consequences of the analysis are examined. Section 5 discusses the question whether the case split on the possessor in Udmurt should be seen as an instance of possessor raising. Finally, in Section 6, the theory proposed in the preceding sections is embedded within a broader typology of case stacking phenomena. Section 7 concludes. 


\section{Empirical background}

In this section, we broaden the empirical basis for the analysis of the case split in Udmurt. Section 2.1 discusses the exact distribution of both possessor cases in Udmurt and arrives at the empirical generalization which paves the way for the case stacking analysis. In Section 2.2, the functions of the ablative apart from those in the possessor construction are examined in comparison with other cases.

\subsection{Distribution of the ablative: finding the correct generalization}

In this section, we will apply a number of syntactic tests to the possessor construction in Udmurt to find out in which syntactic context the ablative possessor is attested and in which it is not. Traditionally, in any of the descriptive works on possessor case in Udmurt, the generalization is that a possessor receives ablative if the DP which contains the possessor is the direct object of the clause; the genitive is used elsewhere. However, the term direct object is not precisely defined in these works. As far as we can see, there are three possible interpretations of this term. First, direct object could refer to a DP bearing the thematic role patient. Second, it could refer to a particular position in the tree. In this case, direct object would mean something like being contained in the VP on the surface. Third, the term direct object could refer to all DPs which carry accusative case. The occurrence of the ablative in example (1b) is compatible with each of these interpretations. Therefore, we tested the hypotheses against data for which they make different predictions.

We start with the first interpretation according to which the possessor of a DP with the macro-role patient receives ablative; in a DP with any other theta-role it should bear genitive. A relevant test case for that hypothesis is the active-passive alternation. Take as a starting point a transitive verb that has a DP with an ablative possessor as its internal argument and assigns the patient role to that DP, cf. (2a). If this verb is passivized, the DP with the possessor becomes the sole argument of the passivized verb. Since passivization does not change theta-roles, the DP containing the possessor still bears the patient role and should thus get ablative according to hypothesis 1 . However, as (2b) shows, this prediction is not borne out. The possessor in the sole argument DP of a passivized verb receives genitive even if this DP bears the patient role. The first interpretation is thus falsified. 
(2) Possessor case in active-passive alternation:
a. Petyr Masha-leš puny-z-e zhug-i-z
Peter Masha-ABL dog-3SG-ACC beat-PST-3SG
'Peter beat Masha's dog.'
b. Masha-len/*-leš puny-jez zhug-em-yn val
Masha-GEN/-ABL dog-3SG beat-PARTC-INES AUX.PST
'Masha's dog was beaten.'

Next, we test whether the second interpretation makes the correct predictions: only if the DP immediately dominating the possessor remains in its VP-internal base position does the possessor receive ablative. Since Udmurt is a head-final language with predominant SOV order, it cannot be read off of the surface position of the internal argument relative to the verb whether the argument DP is still in the VP or whether it has moved out of the VP; it will precede the verb in any case. We therefore need other means to make sure that the DP with the possessor is indeed in the VP.

We control for the VP-internal position of the DP with adverbs that mark the VP-boundary. Example (3) is based on the passivized sentence in (2b). In addition, it contains a manner adverb. There is evidence that manner adverbs are very low in the structure: in a sentence with a sentential adverb, a temporal adverb and a manner adverb, the manner adverb must be closest to the verb; none of the other adverbs can be placed after the manner adverb. We thus take the manner adverb to mark the VP boundary. With this in mind, look at the example in (3). Since the DP with the possessor is to the right of the manner adverb, it must be in the VP. ${ }^{2}$ The possessor in that DP still receives genitive case. This falsifies the second interpretation, since it would predict ablative case instead of genitive case on the possessor of a VP-internal possessum.

\section{(3) Manner adverb:}

$\begin{array}{llll}\text { Tuzh zol Masha-len puny-jez } & \text { zhug-em-yn } & \text { val } \\ \text { very strong } & \text { Masha-GEN dog-3SG } & \text { beat-PARTC-INES } & \text { AUX.PST.SG } \\ \text { 'Masha's dog was beaten brutally.' } & \end{array}$

Further evidence that the sole argument of a passivized verb that contains a possessor can stay in its VP-internal base position comes from topicalization and

2 We assume that Udmurt either lacks an EPP-feature (as was claimed for e.g. German (Grewendorf 1989; Diesing 1992)) or that the EPP-feature can be discharged differently (as proposed in Alexiadou and Anagnostopoulou 1998). Hence, the subjects of a passivized clause can remain in situ in the VP. We take this to be an unproblematic assumption for our purposes. 
coordination. In (4) the constituent consisting of the passivized verb and its sole argument is topicalized. The fact that the low manner adverb and the passive auxiliary (which realizes a functional head in the extended verbal projection) are stranded suggests that this is an instance of VP topicalization. Crucially, the possessor in the VP-internal DP receives genitive, which again falsifies the second interpretation.

(4) VP topicalization:

[Masha-len puny-jez zhug-em-yn ] tuzh zol val
Masha-GEN dog-3SG beat-PARTC-INES very strong AUX.PST.SG
Lit: 'Masha's dog beaten brutally was.'
'Masha's dog was beaten brutally.'

Furthermore, the constituent consisting of the passivized verb and its sole argument can be conjoined with an equivalent constituent to the exclusion of the preceding manner adverb and the passive auxiliary, cf. (5). Importantly, the adverb and the auxiliary can have scope over both conjuncts as indicated in the translation. Again, this suggests that two VPs have been conjoined. Nevertheless, the possessor of the DP in the VPs receives genitive case, in conflict with the second interpretation.

(5) VP coordination:

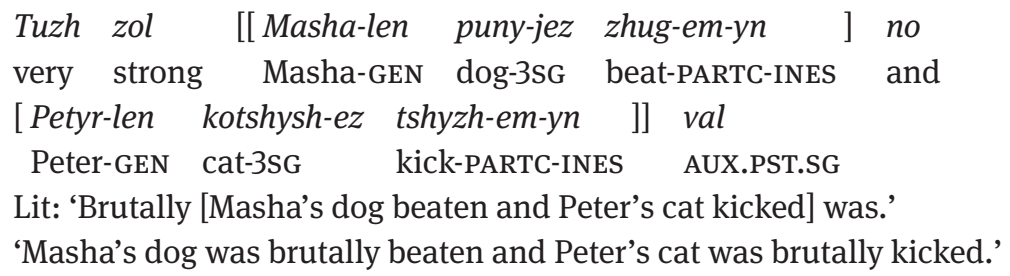

So far we have excluded the first and the second interpretation; only the third interpretation remains. This leads us to the following generalization:

(6) Empirical generalization:

The possessor in Udmurt bears ablative if the XP immediately dominating the possessor bears the accusative marker. The possessor bears genitive elsewhere.

All the data seen so far are compatible with (6). This generalization is furthermore in line with the following observations: First, a possessor contained in a DP that bears a case different from accusative receives genitive case. This was shown in 
(1a) for nominative case and will be shown for a possessor in a genitive DP in (11). (7) and (8) illustrate this for dative and ablative (two semantic cases). In (7), the verb akyltnï 'to bother' assigns dative instead of accusative to its internal argument. If the dative marked argument contains a possessor, this possessor must not bear ablative but genitive instead. The same holds for ablative marked arguments, as shown in (8). This is correctly predicted by the generalization in (6).

(7) Dative assigning verb:

Petyr [Masha-len/*leš suzer-ez-ly ] akylt-e

Peter Masha-GEN/ABL sister-3SG-DAT bother-PRES.3SG

'Peter is bothering Masha's sister.'

(8) Ablative assigning verb:

$\begin{array}{llll}\text { Mon } & \text { [Petyr-len }{ }^{*} \text { leš } & \text { puny-jez-leš ] } & \text { mözm-is'ko } \\ \text { 1SG } & \text { Peter-GEN/ABL } & \text { dog-3SG-ABL } & \text { miss-PRES.1SG } \\ \text { 'I miss Peter's dog.' } & & \end{array}$

The second observation that is compatible with the generalization in (6) concerns ECM constructions. In Udmurt ECMs, the embedded clause is nominalized. The subject of the nominalized clause usually bears genitive instead of nominative. This can be seen if a nominalized clause is used as a sentential subject:

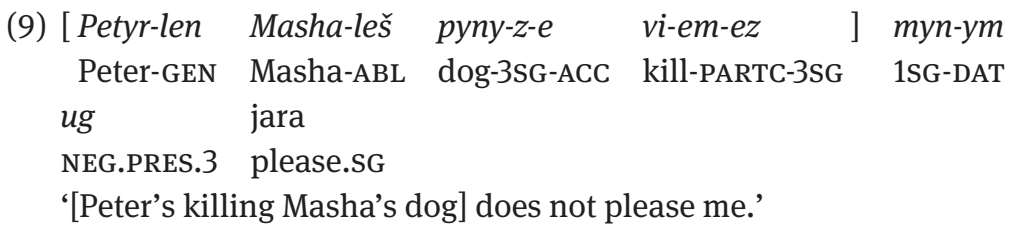

If, however, the nominalized clause is embedded under an accusative assigning ECM verb, the subject of the nominalized verb must bear ablative instead of genitive, cf. (10). This is expected given the generalization in (6): a DP that usually bears genitive carries the ablative marker if the XP immediately dominating it is assigned accusative (here, by matrix v). Example (10) furthermore shows that the case split not only concerns prototypical possessors as in Peter's head but that possessor is to be understood more abstractly as 'DP which usually bears genitive'. ${ }^{3}$

3 A reviewer points out that another possibility to test the generalization in (6) would be a postposition governing accusative case. Unfortunately, there are no such postpositions in Udmurt. 


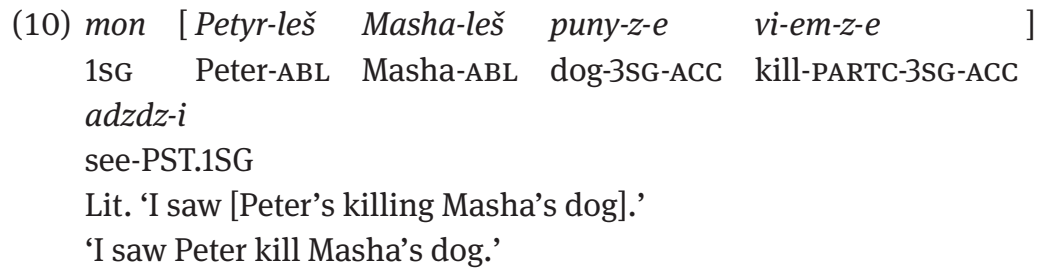

Finally, consider what happens to case marking in recursive possessor constructions: if a DP that contains multiple possessors is not assigned accusative, as e.g. in (11) where it is the sole argument of an intransitive verb that bears nominative (a zero marker), all possessors in that DP bear genitive. If, however, a DP that contains multiple possessors is assigned accusative, only the structurally highest possessor gets ablative; the possessors that are more deeply embedded still get genitive marking, cf. (12) (see also Edygarova 2010: 177).
(11) Masha-len apaj-ez-len puny-jez iz'-e
Masha-GEN sister-3SG-GEN dog-3SG sleep-PRES.3SG
'Masha's sister's dog is sleeping.'
(12) Petyr Masha-len apaj-ez-leš puny-z-e zhug-i-z
Peter Masha-GEN sister-3SG-ABL dog-3SG-ACC beat-PST-3SG
'Peter has beaten Masha's sister's dog.'

This pattern is predicted by the generalization in (6): the lower possessor Masha is immediately dominated by the DP Masha's sister that bears ablative. But since it is accusative marking of the dominating DP that is a prerequisite for ablative marking on the possessor, the lower possessor must bear genitive. The highest possessor receives ablative marking because the DP dominating it gets accusative case. ${ }^{4}$ To conclude, only hypothesis 3 is compatible with all the data, viz., it is the

\footnotetext{
4 Since we will pursue a syntactic case stacking analysis for Udmurt, it is interesting that a similar constraint holds in Lardil (Tangkic, Australia), a language with overt case stacking: Richards (2013: 50-51) notes that whereas the structurally highest possessor exhibits overt case stacking in Lardil - it bears the prototypical possessor case genitive plus the case that the dominating DP is assigned - lower possessors can only bear a single genitive marker, i.e., they do not allow for genitive stacking. Richards argues that this is not simply a haplology effect because it is also impossible to stack any other case or tense marker on top of the genitive although these markers can usually stack on top of case markers. Richards does not offer an explanation for this constraint. For a proposal on how to derive this effect in Udmurt, see Section 3.
} 
case value of the DP containing the possessor that is the decisive factor for the case split in Udmurt, and not its GF.

\subsection{Functions of the ablative}

Udmurt has 15 cases altogether, as shown in (13). We divide them into two groups: structural and semantic cases. Structural case is assigned to a DP in a certain position in the syntactic structure independent of the theta-role of the DP in that position. The group of structural cases comprises nominative, accusative, and genitive. Semantic case encodes a semantic relation (involving theta-role assignment) between the DP and the governing head. Semantic cases are typical adjunct cases (Wunderlich and Lakämper 2001; cf. theta-related case in Řezác 2008). This distinction plays an important role in the analysis in Section 3.

(13) Case system in Udmurt:

\begin{tabular}{|l|ll|}
\hline Structural cases & \multicolumn{2}{|c|}{ Semantic cases } \\
\hline nominative & dative & inessive \\
accusative & ablative & elative \\
genitive & abessive & illative \\
& adverbial & egressive \\
& instrumental & transitive \\
& approximative & terminative \\
\hline
\end{tabular}

Let us concentrate on the ablative. The core function of the ablative marker is to encode adjuncts expressing source and origin (cf. (14a)). In addition, it has a number of other functions in Udmurt (cf. Edygarova 2009; Winkler 2001): it is used to express comparison (cf. (14b)), the cause of an action (cf. (14c)), the material something is made of (cf. (14d)), and it encodes possessors. Furthermore, the ablative is governed by some postpositions (cf. (14e)) and verbs (cf. (14f)).

(14) Uses of the ablative (Edygarova 2009: 108; Winkler 2001: 22-23):
a. mon so-leš gožtet bašt-i
I he-ABL letter.ACc get-PST
'I got a letter from him.'

source 
b. vit'ton-lěs uno

fifty-ABL more

'more than fifty'

c. so-leš žad'-em

comparison

he/she-ABL be tired-PST.3SG

'(he) got tired with him'

cause

d. basma-leš leśt-em arberi-os

cloth-ABL make-PARTC thing-PL

'things which are made from cloth'

material

e. ta-leš ažlo

DEM-ABL before

'before this' (temporal)

postposition

f. mon Petyr-leš mözm-is'ko

1SG Peter-ABL miss-PRES.1SG

'I miss Peter.'

verb

Thus, the ablative appears in a variety of contexts that are not reducible to its core function. What is remarkable is that these contexts do not seem to form a natural class. This becomes even more obvious when looking at the distribution of the other semantic cases: they are much more restricted in their applicability (see Winkler 2001: 16ff. for an overview). Local cases only occur in their core function, other cases like the instrumental, e.g., can be additionally governed by verbs and postpositions if they are semantically compatible with the core function of the respective case. The instrumental, for example, is used in comitative as well as in prototypically instrumental function only. Since these two functions almost always pattern together (as in the use of the English preposition with which also covers both cases), it seems plausible to treat these as a kind of "macro-function". Accordingly, the instrumental is governed by verbs and postpositions that relate to this macro-function such as ešjaškini (to become friends), todmatskini (to get to know), čoš (together with) or artin (beside).

We conclude from these facts that the ablative marker is the default semantic case marker in Udmurt. This assumption will be important for the analysis of the ablative case on the possessor and is formally implemented in Section 3. ${ }^{5}$

5 It has also been argued for other languages that there is a default semantic case. Vainikka (1993) e.g. argues that the elative is the default semantic case for adjuncts in Finnish because it appears in a variety of contexts that are not related to its canonical locative function. This canonical function is similar to that of the ablative in Udmurt: both encode the relation 'from x'. 
In this section, we have provided evidence that the decisive factor that governs the distribution of the ablative on the possessor is not the GF but rather the case value of the immediately dominating XP. Also, we have argued that the ablative is the default semantic case marker in Udmurt. In the next section, we present a derivation of the facts presented in this section that crucially relies on case stacking and the default nature of the ablative marker.

\section{Deriving the new generalization}

The generalization in (6) with the case of the XP immediately dominating the possessor as the decisive factor for the Udmurt case split facilitates a reanalysis of the phenomenon in terms of case stacking: We propose that the D head in Udmurt only assigns genitive case. If the possessor DP is an argument of another DP which is assigned accusative later on in the derivation, the possessor DP receives accusative in addition. The ablative marker can then be analyzed as the result of case stacking: it is the realization of abstract genitive and abstract accusative stacked on the possessor in the syntax; there is no abstract ablative case on the possessor.

The derivation of the generalization in (6) is divided into three subparts that contain assumptions about the lexicon, the syntax of case assignment and the morphological realization of abstract case features. We consider them in turn.

\subsection{The lexicon}

As has already been introduced in Section 2.2, Udmurt exhibits a rich case system. We divide the cases into groups of structural and semantic cases, cf. (15). ${ }^{6}$ The defining property to distinguish these groups are the positions to which they are assigned in the syntax. We assume that semantic cases are assigned to complements of (empty) adpositions whereas structural cases are not. They are assigned by the functional heads $\mathrm{v}, \mathrm{T}$, and $\mathrm{D}$.

6 This opposition has been widely adopted in the literature on Uralic languages. See e.g. Vainikka (1993); Kiparsky (2001) for empirical and theoretical arguments from Finnish as well as Ylikoski (2011) for diachronic arguments from Proto-Uralic. 
(15) Case system in Udmurt:

\begin{tabular}{|l|ll|}
\hline Structural cases & \multicolumn{2}{|c|}{ Semantic cases } \\
\hline nominative & dative & inessive \\
accusative & ablative & elative \\
genitive & abessive & illative \\
& adverbial & egressive \\
& instrumental & transitive \\
& approximative & terminative \\
\hline
\end{tabular}

We assume that abstract cases are decomposed into the binary features $\left[ \pm\right.$ obl(ique)] and $[ \pm$ gov(erned) $] .{ }^{7} \mathrm{~A}$ case is $[+$ gov $]$ if it is governed in the sense that it is assigned by a verb or a postposition. ${ }^{8}$ In the case of verbs, it is the accusative, and in the case of postpositions, it is a semantic case. [+obl] characterizes those cases that are not standardly assigned to the core arguments of a verb in a given argument encoding pattern. In a language like Udmurt with an accusative alignment pattern, the cases standardly assigned to the core arguments, i.e., the [-obl] cases, are nominative and accusative; all remaining cases are [+obl]. ${ }^{9}$ As a consequence, all semantic cases are represented as [+obl,+gov]. The decomposition for the three structural cases nominative, accusative and genitive is shown in (16a); the decomposition for the semantic cases is given in (16b).

(16) a. Structural cases:

$$
\begin{array}{ll}
\text { NOM } & {[-\mathrm{obl},-\mathrm{gov}]_{\text {case }}} \\
\text { ACC } & {[-\mathrm{obl},+\mathrm{gov}]_{\text {case }}} \\
\text { GEN } & {[+\mathrm{obl},-\mathrm{gov}]_{\text {case }}}
\end{array}
$$

b. Semantic cases:

$$
\begin{array}{ll}
\text { ABL } & {[+\mathrm{obl},+\mathrm{gov}]_{\text {case }},[-\mathrm{f},-\mathrm{g}, \ldots]_{\text {case }}} \\
\text { DAT } & {[+\mathrm{obl},+\mathrm{gov}]_{\text {case }},[+\mathrm{f},-\mathrm{g}, \ldots]_{\text {case }}} \\
\text { INSTR } & {[+\mathrm{obl},+\mathrm{gov}]_{\text {case }},[-\mathrm{f},+\mathrm{g}, \ldots]_{\text {case }}} \\
\ldots &
\end{array}
$$

7 Both of these features go back to Bierwisch (1967) and have, since then, been argued for in a number of papers on independent grounds. See especially Chvany (1986) but also Franks (1995); Wiese (2001); Müller (2004) for arguments in favor of the feature [ \pm obl(ique)] and Wiese (2001); Müller (2004); Weisser (2006) for arguments in favor of [ \pm gov(erned)]. Both features have also been used and, to a certain extent argued for, in Halle (1997); Halle and Vaux (1997) (though note that [ ${ }$ governed] is labeled [ \pm superior] there even though it is defined in exactly the same way as we do here).

8 Indeed, there is no verb or postposition in Udmurt that governs genitive; hence, genitive is a [-gov]-case.

9 In this system, genitive is classified as a structural case but at the same time it is represented as an oblique case. See also Halle (1997) for a case decomposition that characterizes genitive as oblique and structural. 
Since the semantic cases are all specified as [+obl,+gov], further features are necessary to distinguish between them. We assume that this is done by a set of semantic features which are abstractly represented as $[ \pm \mathrm{f}],[ \pm \mathrm{g}]$, etc. in (16b); their exact meaning does not matter for our purposes. As a consequence, the semantic cases are more complex than the structural cases (cf. Béjar and Massam 1999). ${ }^{10}$ They consist of two case feature sets: like the structural cases they have a feature set that contains values for $[ \pm$ obl $]$ and $[ \pm$ gov], but unlike the structural cases they have a second set of semantic features.

With this background on the cases and their representation in Udmurt, we turn to our assumptions about the lexical properties of the relevant items. First, since there are cases that consist of two case feature sets, case bearing elements in Udmurt must have the possibility to receive up to two case feature sets. For this reason, we assume that all case bearing elements in Udmurt have exactly two case slots. This is illustrated in (17a) for D and (17b) for N. ${ }^{11}$

$$
\text { a. } \mathrm{D}\left\{[]_{\text {case }},[]_{\text {case }}\right\} \text { b. } \mathrm{N}\left\{[]_{\text {case }},[]_{\text {case }}\right\}
$$

Each of these "slots" can be assigned a structural or a semantic case feature set, each of which is a bundle of binary case features. Consequently, D and N heads (as any other case bearing elements) can be assigned up to two abstract case feature sets. This is to say that Udmurt exhibits syntactic case stacking (on case stacking see e.g. McCreight 1988; Nordlinger 1998; Merchant 2006; Pesetsky 2014; Richards 2013; see Section 6 for further discussion). A number of languages can overtly stack cases on the possessor: The possessor carries the genitive marker plus the case marker realizing the case assigned to the DP containing it. An example from Huallaga Quechua is given in (18). What we assume is that this stacking

10 In Nanosyntax, semantic cases are also more complex than structural cases; cf. Caha (2009). 11 This may seem stipulative at first, but there are quite a number of languages with overt case stacking where the maximum of cases that can stack is also two. One such language is Thalanyji (Austin 1995: 373). Here, the possessor of the object bears the possessor case (i.e. dative in Thalanyji) and in addition, it bears the case of its head noun (also dative). More than two cases, however, can never stack in Thalanyji. This is shown by the fact that the possessor of the possessor of the object carries dative inflection only twice as well.

(i) Double Case Marking in Thalanyji:

$\begin{array}{llll}\text { Juma jirrilarri-a } a \text { thuthu-wu } & \text { nganaju-wu } & \text { yakan-ku-wu } \\ \text { child.ABS be.afraid-PRES } & \text { dog-DAT } & \text { I.DAT-DAT } & \text { spouse-DAT-DAT } \\ \text { 'The child is afraid of my wife's dog.' } & & \end{array}$

We will see in Section 6 that Udmurt instantiates only one case within the typology of possible case stacking patterns. 
happens in Udmurt syntax as well (stacking of abstract cases), although the cases cannot be stacked overtly in Udmurt (stacking of case exponents). We come back to this issue in Section 3.3.

(18) Case stacking in Huallaga Quechua (Pylkkänen 2002):

$\begin{array}{lll}\text { Hipash-nin-ta } & \text { kuya-: } & \text { Hwan-pa-ta } \\ \text { daughter-3Poss-Acc } & \text { love-1 } & \text { Juan-GEN-ACC } \\ \text { 'I love Juan's daughter.' } & \end{array}$

Since there are two case slots on D and $\mathrm{N}$ heads in Udmurt, a comment on the Case filter is necessary: in order to fulfill the Case filter, every DP must receive at least one abstract case, i.e., one case feature set; the second slot can remain unvalued. ${ }^{12}$

The second assumption concerns the valuation potential of structural and semantic cases: semantic cases fill two case slots on a head rather than one like structural cases (similar ideas have been put forward by Béjar and Massam 1999; Richards 2008). The reason for this is that semantic cases are more complex than structural cases: they consist of a structural and a semantic case feature set. If a semantic case is valued on D (or N), one of D's case slots is filled by the syntactic case feature set $[ \pm$ obl, \pm gov]; the second slot is filled by the semantic case feature set. It is not possible to value only one of the two sets of the semantic case on D; both of them must be copied under Agree with D, they form a unity. An important consequence of this assumption is that only two structural cases can stack. One structural and one semantic case or two semantic cases cannot stack because one semantic case alone already fills the two case slots on D (or N) and no further valuation is possible then. ${ }^{13}$ In what follows, the relevant configuration will be

12 Note that such an assumption seems to be inevitable when it comes to case stacking: In languages that exhibit case stacking, no case bearing element inherently requires more than one case; case stacking always only arises in certain syntactic configurations. This is exemplified by (18), where the noun daughter bears only the accusative, while Juan bears the genitive and the accusative.

13 It has been repeatedly noted in the literature (Babby 1984, 1990; Moravcsik 1995; Richards 2013) that the structural/semantic (or inherent) case distinction plays a central role in case stacking languages: often, XPs with a structural case $\mathrm{S}$ do not allow for stacking of another case $\mathrm{R}$; rather, the structural case $\mathrm{S}$ is replaced by case $\mathrm{R}$, i.e., there is no overt stacking. In contrast, XPs with a semantic case either allow for stacking or block stacking, too, but the semantic case is not replaced by case R (see e.g. Japanese topic marking, the Russian genitive of negation, case stacking in Lardil). Although the constraints on stacking in Udmurt are different, the split between these two types of cases is important for Udmurt as well, since stacking is only possible for structural cases. 
one in which the head of the possessor DP has been assigned genitive case and is to receive a semantic case from an external head: the prior assignment of the genitive blocks valuation of the semantic case because there are only two case slots on the D head and genitive+semantic case would need three slots. Thus, only one structural case can stack on the genitive. ${ }^{14}$

\subsection{The syntax}

As indicated before, we assume that abstract case, represented by decomposed case features, is assigned by functional heads to arguments under Agree. D assigns abstract genitive case to a possessor in SpecD; transitive $\mathrm{v}$ assigns abstract accusative case to the internal argument, and T assigns abstract nominative case to the external argument under c-command. ${ }^{15}$ For the sake of concreteness, we assume that semantic cases are assigned to their complements by zero adpositions (cf. Pylkkänen 2002; Řezáč 2008; Hole 2008, among others).

In order to model DP-internal case concord, we assume that abstract cases are assigned to all case-bearing elements in the DP via Multiple Agree (Hiraiwa 2001; Vainikka and Brattico 2014), i.e. to D and N heads (and other DP-internal heads such as heads of number and adjectival projections if they are present). That means that the case of a functional head can be assigned to more than one element. ${ }^{16}$ Only those elements that have an unvalued case feature can receive a value. In this system, case assignment for abstract structural and semantic cases is identical, i.e., both are assigned in the syntax.

14 The fact that DPs can bear a semantic case motivates that $\mathrm{N}$ and D heads must have at least two case slots because a semantic case needs to value two case slots. That these heads have exactly two case slots and not more is motivated by the distribution of genitive and ablative in multiple possessor constructions: if $\mathrm{D}$ and $\mathrm{N}$ heads had more than two case slots, the analysis in Section 3 would wrongly predict that not only the structurally highest possessor but also more deeply embedded possessors should get ablative marking. See Section 6 on cross-linguistic variation and footnote 11 concerning the number of cases that can stack.

15 Under the assumption that the case assigner must c-command the DP, a problem with genitive case assignment arises: we assume that possessor DPs are specifiers within DP. Consequently, they are not in the c-command domain of the D head which assigns genitive case. In order to solve this problem one could adopt the search algorithm in Řezáč (2004).

16 There are two related proposals on concord that would also be compatible under certain additional assumptions: (i) Case is assigned to the sister node $\delta$ of a case assigner and, unless blocked by independent principles, the case value on $\delta$ spreads downward in the domain dominated by $\delta$ (see Matushansky 2008; Bjorkman to appear; Erlewine 2013); (ii) concord as feature-sharing (cf. Frampton and Gutman 2006; Schoorlemmer 2009). 
Given these assumptions, case assignment in clauses with a possessor proceeds as follows. We start with genitive assignment in the DP. As shown in (19), the possessor is merged as the specifier of the D head of the possessum. D assigns genitive [+obl,-gov] to its specifier. More precisely, it assigns it to the $\mathrm{N}$ head of the possessor and thereby values one of its two case slots; in addition, given the possibility of Multiple Agree, the $\mathrm{D}$ head in the box assigns genitive to the D head that selects the possessor NP, filling one of its two case slots, too. The second case slot on the $\mathrm{D}$ and the $\mathrm{N}$ head in the possessor DP remains unvalued.

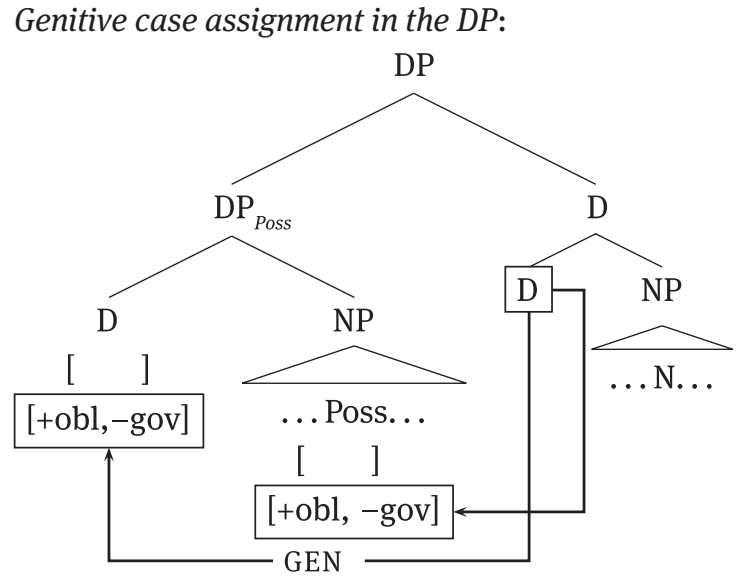

In the following derivations, the entire DP in (19) is merged into different positions in the clausal spine. The initial step of DP-internal genitive assignment to the $\mathrm{D}$ and $\mathrm{N}$ head in the possessor DP always takes place, but for the sake of clarity we do not indicate it anymore in the following trees. For the same reason, we will only indicate case assignment to D heads in what follows; we omit case assignment to $\mathrm{N}$ heads (the possessum), but the reader may verify that no complications arise for case assignment to them; the $\mathrm{N}$ head will always receive the same case as the D head that selects the NP projected by N.

In the first context, the DP containing a possessor is merged as the external argument of a transitive verb in Specv. This DP is assigned nominative by the c-commanding T head, cf. (20). T values nominative [-obl,-gov] on the D head of the possessor DP contained in the external argument DP. The head of the possessor already bears genitive, but the second slot is still available for nominative from T; genitive and nominative thus stack on this D head. In addition, $\mathrm{T}$ assigns nominative to the $\mathrm{D}$ head of the external argument, filling one of the two case slots on this D head. 
(20) Nominative case assignment:

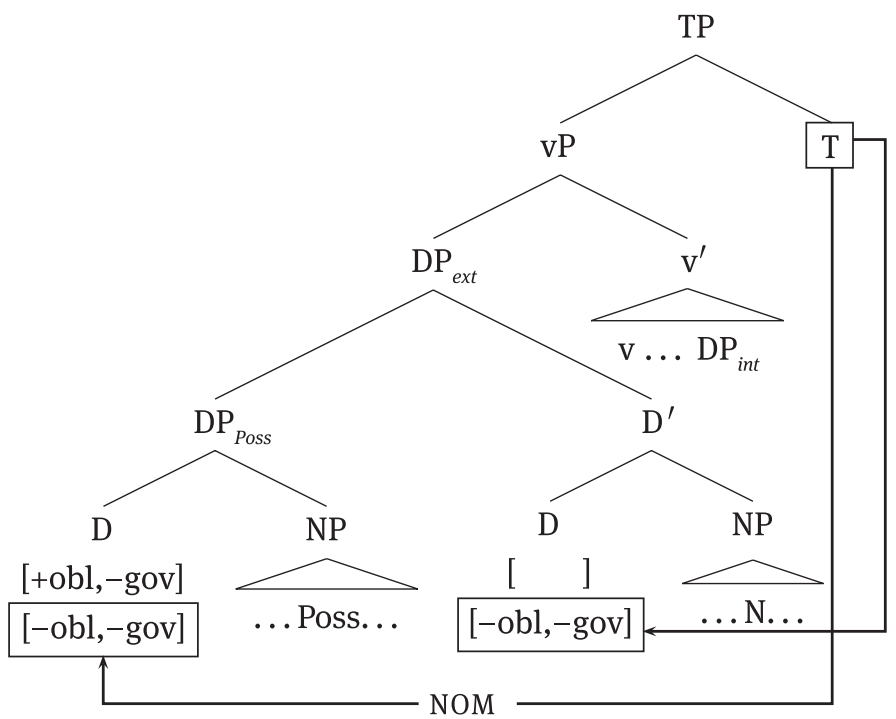

Virtually the same happens if the DP in (19) is merged as the internal argument of a transitive verb. In that position, $v$ assigns accusative [-obl,+gov] to the D head of the internal argument, filling one of its two case slots, and to the D head of the possessor contained in the internal argument, filling its remaining case slot. The result is stacking of genitive and accusative on the possessor's D head.

(21) Accusative case assignment:

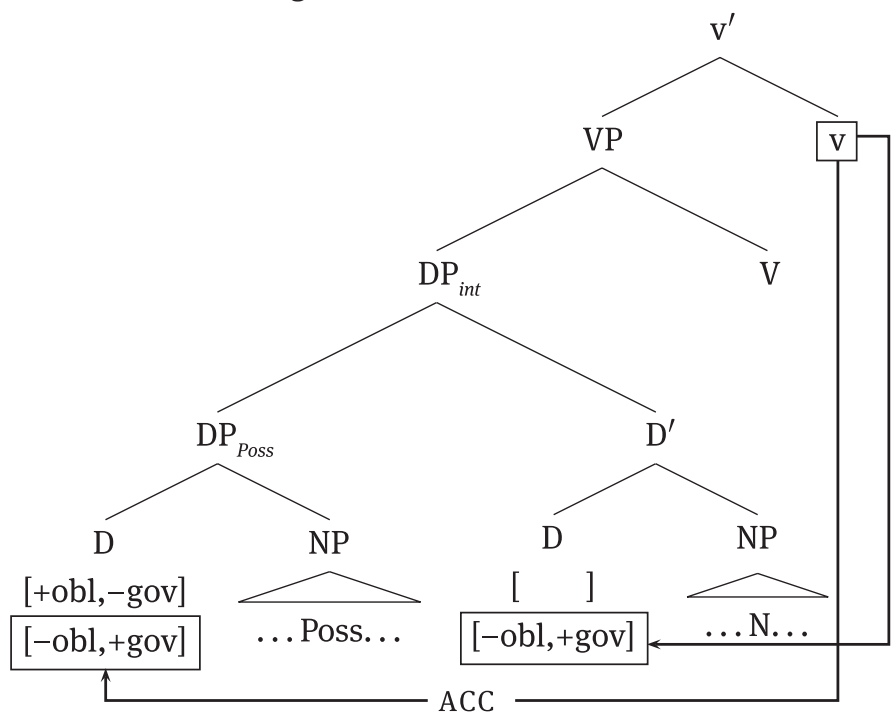


In (22), the DP containing the possessor is assigned a semantic case. This happens if the DP is the sister of a zero postposition. This PP may, for example, be merged as the internal argument of V, cf. (22). For concreteness, we illustrate semantic case assignment with dative, but the derivation would be the same with any other semantic case value. In (22), P assigns dative [+obl, +gov], $[+\mathrm{f},-\mathrm{g}, \ldots$. . ] the $\mathrm{D}$ head of the internal argument. Since semantic cases are complex, they value both case slots of this D head: one with the structural feature set [+obl,+gov], and the other one with the semantic case feature set $[+f,-g, \ldots]$. Crucially, however, $\mathrm{P}$ cannot assign dative to the possessor. The reason is that one case slot of this head is already filled with genitive. Thus there is not enough 'space' left on the D head of the possessor for the dative case. Consequently, there is no case stacking on the possessor if the case assigned to the dominating DP is a semantic case. ${ }^{17}$

(22) Dative case assignment:

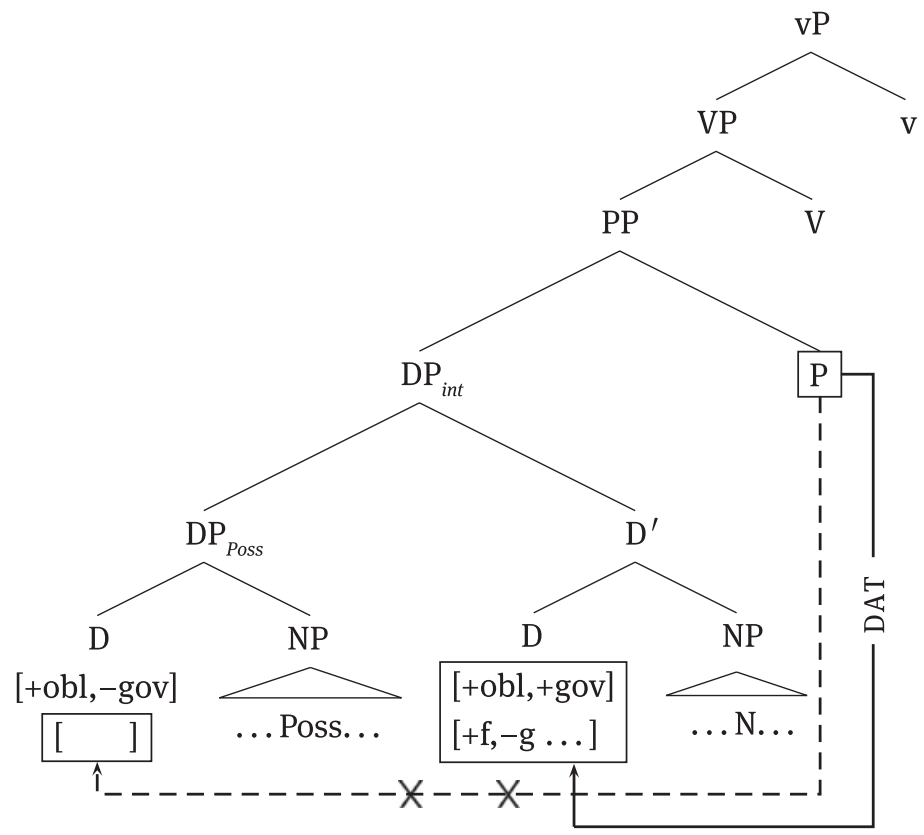

17 The second case slot of D remains unvalued in (22). This raises the question whether the empty case slot on the possessor can be valued by a structural case assigned by a higher head; it could, for example, be valued accusative from $v$ in a ditransitive construction where the PP functions as the indirect object. This would predict ablative marking on the possessor of the indirect object. But this is not borne out. To prohibit accusative assignment to the empty slot, one could assume the PP to be an absolute barrier for Agree. See Section 4.2 for a discussion of the boundedness of case assignment. 
Finally, consider a case of double possessors with double genitive assignment to the most deeply embedded possessor. In (23), the structurally highest DP contains a possessor $\mathrm{DP}\left(\mathrm{DP}_{\text {Poss }_{1}}\right)$ in its specifier which in turn contains a possessor $\left(\mathrm{DP}_{\text {Poss }_{2}}\right)$. Within $\mathrm{DP}_{\text {Poss }_{1}}$, the lower possessor $\left(\mathrm{DP}_{\text {Poss }_{2}}\right)$ receives genitive from $\mathrm{D}_{1}$. Next, $\mathrm{DP}_{\text {Poss }_{1}}$ is merged and $\mathrm{D}_{3}$ assigns genitive to all elements that are dominated by $\mathrm{DP}_{\text {Poss }_{1}}$ and still have an empty case slot, including $D_{2}$ and $D_{1}$. As a result, $D_{2}$ bears genitive twice and $\mathrm{D}_{1}$ bears it once, its second case slot is yet unvalued. The complex DP containing the two possessors can now be merged with another head. If it is the sister of a transitive verb, it is assigned accusative by v. Recall that, empirically, in such a configuration only the structurally highest possessor ends up with the ablative, which depends on having received accusative (cf. (12)); the most deeply embedded possessor must bear genitive. This is predicted by the analysis in (12): since the two slots of the lower possessor are already filled with genitive case, accusative can only be assigned to the higher possessor that still has an empty slot available. Since accusative is a prerequisite for a possessor's occurrence with ablative marking, the lower possessor will bear the genitive suffix. The different morphological marking of the two possessors in a multiple possessor construction thus follows from the restriction of the number of case slots in Udmurt (an assumption that will be further discussed in Section 6) and their structural position.

(23) Double possessors: genitive case assignment:

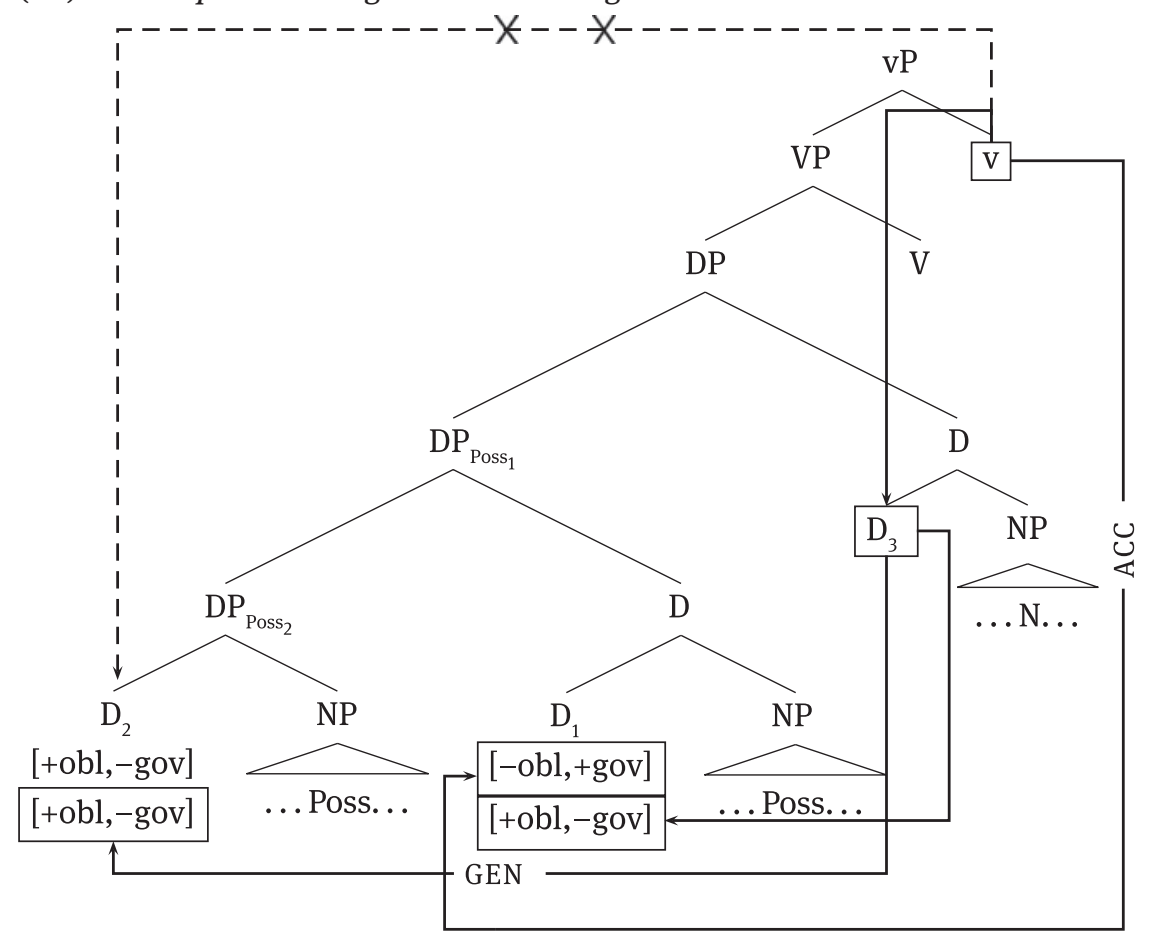


In the next subsection, we will show how exactly a D head with the accusative value stacked on the genitive value ends up with the ablative case morpheme.

\subsection{The morphology}

We assume a postsyntactic realizational morphology. The syntax only operates with abstract feature bundles that are realized by exponents in the morphological component. For concreteness, we adopt the framework of Distributed Morphology (DM, Halle and Marantz 1993, 1994): vocabulary items (VIs), which are pairings of morphosyntactic features with phonological information, are inserted into terminal nodes in the syntactic structure. VIs can be underspecified with respect to their morphosyntactic features which leads to competition for insertion. This competition is resolved by the Subset Principle and Specificity: only the most specific matching VI can be inserted into a terminal node, i.e., the VI that has the largest subset of the morphosyntactic features of the terminal.

In the present discussion, the question is how the abstract binary case features are realized by case exponents. We assume that case VIs in Udmurt are exclusively specified for positive features, cf. (24). ${ }^{18}$

18 One reviewer asks whether there is any theoretical significance to the fact that the VIs only make reference to positive feature values and whether that means that case features could be represented by privative features in the first place. We are unsure about the first question. At this point this is just an observation, which nicely patterns with some claims made in the literature (see e.g. Zwicky 1977; Harley and Ritter 2002; Nevins 2003) but it is not clear to us whether that indicates that these claims are correct. As for the second question, the answer is that privative features are not an option. The reason is that the blocking effects could not be derived straightforwardly. An integral part of our analysis is the assumption that only two structural cases can stack, but a semantic case cannot stack on any other case. We do not see how stacking of a semantic case on top of the nominative can be blocked if the nominative is represented by the absence of privative case features (which it would if the privative case features replace the positively valued features in the present analysis). Note that this is not a framework-specific problem. For example, one could assume a nanosyntactic approach to case assignment in which cases are decomposed into privative case features (or rather heads, Caha 2009). Since there is no case assignment in nanosyntax, but only case checking, case stacking must be implemented by allowing a DP to check against different case checking heads, and consequently, allowing more than one DP to check against one structural head. For reasons of space, we cannot elaborate on this idea here, but see Assmann (2014) for an explicit proposal. Although these assumptions combined with further assumptions about the spell-out of stranded case peels (see Caha (2009: 157ff.)) can in principle account for the case split on possessors in Udmurt, blocking of case 
(24) Case vocabulary items in Udmurt:

$\begin{array}{llll}{[+\mathrm{obl},+\mathrm{gov},+\mathrm{f}]} & \leftrightarrow & / l i / & (\mathrm{DAT}) \\ {[+\mathrm{obl},+\mathrm{gov}]} & \leftrightarrow & / \text { leš } & (\mathrm{ABL}) \\ {[+\mathrm{obl}]} & \leftrightarrow & / l e n / & (\mathrm{GEN}) \\ {[+\mathrm{gov}]} & \leftrightarrow & / e / & (\mathrm{ACC}) \\ {[]} & \leftrightarrow & \varnothing / & (\mathrm{NOM})\end{array}$

The nominative exponent is the completely underspecified elsewhere marker. The genitive and the accusative exponent are underspecified: they are only specified for one of the two syntactic case features [+obl] and [+gov], respectively. All semantic case exponents are fully specified for the structural case features. In order to distinguish between the various semantic cases, the relevant VIs are specified for the positive semantic features, e.g. in (24) the dative VI is specified for the semantic feature $[+\mathrm{f}]$ in addition to being specified as [+obl,+gov]. How exactly the semantic case features are distributed over the semantic case VIs is of no importance and we thus only indicate the dative VI in (24). Instead, the specification of the ablative exponent is central: this semantic VI is fully specified for [+obl,+gov], as all the semantic case VIs; however, it is completely underspecified for the semantic case features, in contrast to all remaining semantic case VIs. This encodes the default character of the ablative (see Section 2.2): it is in principle compatible with every syntactic context that is specified as [+obl,+gov]; it is, however, often blocked by a more specific semantic case VI.

We can now take a look at the operations that happen in the morphological component. In the last section we assumed that Udmurt has case stacking in the syntax. However, Udmurt obviously does not exhibit overt case stacking (see also Section 6 for a discussion of how Udmurt fits into the typology of case stacking). To implement this, we assume that Udmurt has a filter which excludes the co-occurrence of two case exponents. As a consequence, a problem would arise if case stacking took place in the syntax because only a single case exponent can be realized but two abstract case values are present on a terminal. In order to obey the filter, a repair operation applies in the morphological component prior to vocabulary insertion: the two case feature sets on the terminal node ( $D$ or $N$ ) have to fuse into a single feature set. Fusion is thus a set-building operation which unifies the features of the two case slots into one: several instances of identical values are reduced to a single instance of that value (see Noyer 1992; Halle and Marantz 1993 for a similar but not identical concept of fusion). The results

stacking remains a problem in this framework as well and cannot easily be reduced to general locality constraints. See footnote 21 for a related discussion. 
of fusion are shown in (25). To the left of the fusion arrow it is shown which abstract cases (are supposed to) stack; to the right, the resulting feature set is indicated. The VI from (24) that realizes this fused feature structure is given in brackets. ${ }^{19}$

(25) a. genitive + dative:

$$
[+ \text { obl, }- \text { gov }]+[\quad] \quad \stackrel{\text { fusion }}{\longrightarrow}[+ \text { obl, }- \text { gov }] \quad \text { (=gen. VI /len/) }
$$

b. genitive + nominative:

$$
\text { [+obl, -gov }]+[-\mathrm{obl},- \text { gov }] \stackrel{\text { fusion }}{\longrightarrow}[+\mathrm{obl},- \text { obl, }- \text { gov }] \quad \text { (= gen. VI /len/) }
$$

c. genitive + genitive:

$$
\text { [+obl,-gov }]+[+ \text { obl, }- \text { gov }] \stackrel{\text { fusion }}{\longrightarrow}[+ \text { obl, }- \text { gov }] \quad \text { (= gen. VI /len/) }
$$

d. genitive + accusative:

$$
[+\mathrm{obl},-\mathrm{gov}]+[-\mathrm{obl},+ \text { gov }] \stackrel{\text { fusion }}{\longrightarrow}[+\mathrm{obl},-\mathrm{obl},+ \text { gov, }, \text { gov }] \quad(=\mathrm{abl} \text {. VI /leš/ })
$$

e. nominative + accusative:

$$
[-\mathrm{obl},-\mathrm{gov}]+[-\mathrm{obl},+ \text { gov }] \stackrel{\text { fusion }}{\longrightarrow}[-\mathrm{obl},+ \text { gov, }- \text { gov }] \quad(=\mathrm{acc} . \mathrm{VI} / e /)
$$

We begin with the trivial case in which the $\mathrm{D}$ head of a possessor that has been assigned genitive in the DP is to be assigned an abstract semantic case from an external head in addition, e.g. dative in (25a). Recall that any stacking of an abstract semantic case and the genitive is excluded already in the syntax (cf. (22)). Thus, the D head of the possessor has only one valued case slot in such a context. Consequently, fusion of the genitive feature set with an empty set results in the feature structure of the genitive [+obl,-gov]. The most specific matching VI for this feature set is the genitive VI.

Next, consider the fusion of abstract nominative and abstract genitive in (25b); cf. (20). Since the nominative contributes only negative feature values to the fused feature set, and since VIs only spell out positive feature values, the nominative will never have an impact on the realization of the case features. The most specific matching VI for the fused set is thus determined by the positive feature from the abstract genitive alone.

In the case of multiple possessors, all possessors except for the structurally highest one end up with genitive-genitive stacking (cf. (23)). Since fusion is a set-building operation, the result in (25c) is a representation of the genitive, which is of course also realized by the genitive VI.

The interesting context is the one shown in (25d): abstract accusative and abstract genitive stack (cf. the derivations in (21) and in (23)). If the features of

19 It should be noted that fusion of feature sets is of course not the only possibility to pass the morphological filter. Other possibilities are discussed in Section 6. 
the accusative and the genitive case fuse, they create a new feature set which contains both [+obl] and [+gov]. Crucially, these features must be realized by a semantic case VI, since these VIs are specified for [+obl,+gov] and are thus the most specific matching VIs. The structural case VIs, including the genitive VI, would also match these features but they are less specific than the semantic case VIs. The only matching semantic VI is the ablative VI, since it is the most underspecified semantic case marker. In (25d), the representations before and after fusion contain no semantic features. Thus, all semantic case VIs except for the ablative do not match the context for insertion in (25d). It is because of the underspecification of the ablative VI for these semantic features (which leads to its default nature) that it shows up in this context.

For the sake of completeness, there is another possible combination of abstract case features that does, however, not involve possessors: nominative and accusative, cf. (25e). These could, e.g., potentially stack on the head of an internal argument of a transitive verb: the internal argument receives accusative from $\mathrm{v}$, filling one of its case slots, and nominative from $\mathrm{T}$, filling the second case slot. As before, the nominative with its negative values does not have any influence on the realization of the accusative. The most specific matching item is the accusative VI, in accordance with the empirical facts.

To conclude, the possessor always bears a genitive marker unless it is assigned accusative in addition to genitive in the syntax; in this case, it bears the ablative marker. Crucially, this ablative marker does not realize the abstract semantic ablative case $([+\mathrm{obl},+\mathrm{gov}],[-\mathrm{f},-\mathrm{g}, \ldots])$ on the possessor; rather, it realizes the combination [+obl, + gov] that arises due to fusion of abstract genitive and accusative.

\subsection{Interim conclusion}

Under the assumption that $\mathrm{D}$ and $\mathrm{N}$ heads in Udmurt bear two case slots, Udmurt allows for limited case stacking in the syntax. Postsyntactic morphological fusion unifies the two case slots (see (25)). If abstract genitive and accusative features are combined, the fused case feature set can only be realized by the ablative marker. In all other combinations of the genitive and another structural case, fusion results in a feature structure that must be realized by the genitive marker. The ablative case on possessors is not an abstract case assigned in the syntax (there are no semantic case features on the possessor that are part of the abstract ablative case). The analysis thus crucially relies on the distinction between abstract and morphological case. Importantly, we do not claim that every occurrence of an ablative marker is the result of stacking genitive and accusative in the syntax. 
Ablative marking can also result from the assignment of abstract ablative which is governed by verbs and postpositions.

It should be noted that in the case of genitive and ablative stacking, a new feature representation arises in the morphology ([+obl,+gov]) that was not present in the syntax, i.e. none of the individual abstract cases was specified as $[+$ obl,+gov]; this representation only arises after postsyntactic fusion. As a consequence of fusion, a more specific VI is inserted when genitive and accusative stack: we find the ablative marker instead of the less specific genitive marker. This is the reverse of the effect of impoverishment (Bonet 1991; Noyer 1992; Halle and Marantz 1993, 1994; Bobaljik 2002; Frampton 2002): impoverishment deletes features prior to vocabulary insertion and thus leads to the insertion of a less specific VI. Fusion has exactly the opposite effect without adding new features (i.e. enrichment).

Note also that the analysis presented above naturally accounts for the case pattern with multiple possessors where only the highest possessor can receive ablative case (cf. the derivation in (23)). Lower possessors receive genitive twice, which leaves no slot for the accusative case to be assigned, thus no context is created where the ablative marker can be inserted. This context may only arise on the structurally highest possessor and thus only this possessor can bear the ablative marker. This analysis crucially relies on the restriction that all case bearing items cannot have more than two case slots; otherwise the abstract accusative could spread to more deeply embedded possessors in recursive possessor constructions and these possessors would be wrongly predicted to bear the ablative marker (see also Section 6 for different restrictions and constraints on case stacking).

\section{Theoretical issues}

\subsection{Look-ahead and counter-cyclicity}

In this section, we briefly want to come back to the issues of locality and cyclicity of case assignment raised in the introduction.

It is standardly assumed that syntactic dependencies (including case assignment) neither involve look-ahead nor counter-cyclic operations. Given this assumption, case assignment to the possessor in Udmurt seems to pose a problem: Assume that the D head of the dominating DP can assign either abstract genitive or ablative to the possessor. The choice of the concrete case value depends on which case the D head itself receives. However, this information is not available 
at the point of case assignment to the possessor within the DP because, given cyclicity, the dominating DP is merged into the structure only after case assignment to the possessor took place. Thus either look-ahead or countercyclic case assignment within the DP is required.

The analysis developed in Section 3 overcomes this problem by adopting the possibility of case stacking and the postsyntactic morphological operation fusion. The look-ahead problem does not arise because the D head only assigns a single case (genitive). Hence, there is no need to choose between genitive and ablative assignment in the DP depending on the nature of the external head that will later select the DP. Genitive is always assigned to the possessor. Due to case stacking, the relevant information about the external case is present on the possessor; there, it can be locally manipulated by fusion in the postsyntactic morphological component. Given a late insertion model, fusion influences the case marker that is inserted, which leads to a case split.

\subsection{Locality}

Up to this point, we have been agnostic about the question of whether case assignment in Udmurt is restricted by certain locality constraints. So far, each locality effect in the sense that a head A was too far away from a head B to assign case was derived by means of intervention: some head $\mathrm{C}$ intervening between $\mathrm{A}$ and B fills up B's case slots by assigning its own case (see, e.g. the derivation of the double possessors in (23)). Therefore, A cannot assign case to B. Hence, the question arises whether one even needs further concepts of locality, such as phases.

Vainikka and Brattico (2014), who also assume non-local accusative case assignment, have argued for Finnish that there must be some categories which block case assignment into their complements. The same seems to hold for Udmurt. For example, as one can see in (26), the direct object which receives accusative is modified by a relative clause and the subject of that relative clause bears nominative.

$\begin{array}{llllll}\text { (26) Mon } & \text { ažži-śko } & \text { vorgoron-ez } & \text { kudz-e } & \text { puny/*-jez } & \text { kurch-i-z } \\ \text { I } & \text { see-PRES.1sG } & \text { man-ACC } & \text { which-ACC } & \text { dog/*-ACC } & \text { bit-PST-3SG } \\ \text { 'I see a man who a dog has bitten.' } & & & \end{array}$

If accusative case assignment was completely unbounded, one would expect the accusative assigned by the matrix $\mathrm{v}$ to overwrite the nominative of the embedded 
clause. Hence, the relative clause must not be transparent for case assignment by matrix v.

Such cases can be modeled in various ways. One possibility is the concept of phases $^{20}$ (Chomsky 2001) and it seems that data with relative clauses like (26), PPs in ditransitives (see footnote 17), and adverbial clauses suggest that some concept of nontransparent locality domains is necessary under the present approach. ${ }^{21}$

\section{The structural position of the possessor}

In the preceding sections, we simply assumed that the possessor of a DP is always located in SpecD. This assumption deserves some discussion, because it has been argued for a number of languages with a case split on the possessor that the split arises as a consequence of the fact that the possessor may occupy different structural positions.

In one type of this approach, which is particularly prominent for Uralic languages, the possessor can optionally move to a peripheral position within the $D P$ that is associated with the marked case. In the other type, the possessor moves out of the DP to a position within the $\mathrm{vP}$ where it is assigned case by a functional head in the extended projection of the verb. We argue that none of these movement approaches carries over to Udmurt. There is no evidence pointing to a movement analysis, which leads us to adopt the null hypothesis, namely that the possessor in Udmurt is always in the same position.

20 Note that in the present approach DP cannot be a phase, at least not in Udmurt. If DP was a phase, the NP complement of the D head would already be transfered at the point when the functional heads $\mathrm{v}$ or $\mathrm{T}$ assign case to the DP and would never receive case at all. Thus, the assumption of DP being a phase is incompatible with the assumption of case assignment as Multiple Agree. Note further that this is not only a problem of Multiple Agree, but a problem of case concord in general: assuming that DPs are phases and that case is assigned by a DP-external head, the elements in the complement of $\mathrm{D}$ should be able to receive case after they have been transfered, which is not possible.

21 Assuming additional locality constraints raises the question as to whether all blocking effects can be ascribed to absolute locality constraints rather than to intervention. It seems to us that it is far from obvious how the former possibility would derive the basic case split with possessors as described in Section 3. The problem is that possessive DPs must be transparent in order for the possessor to be able to receive accusative case. On the other hand, the possessor in a DP should not be accessible for assignment of other cases. Thus, DP cannot be a barrier for case assignment in general, instead both intervention and absolute locality are needed. 
We start with the first type of approach according to which the possessor may occupy different positions in the DP. A number of Uralic languages beside Udmurt also show a case split on the possessor, although the factors conditioning the split are different from those found in Udmurt. These languages are, e.g., Hungarian, Finnish, Estonian, and Komi (cf. König and Haspelmath 1998; Nikolaeva 2002). The alternation is best studied in Hungarian in which nominative and dative possessors alternate:

(27) Two possessor cases in Hungarian (Szabolcsi 1994):
a. (a) Mari
kalap-ja
(the) Mari.nom hat-Poss.3sG
'Mari's hat'
b. Mari-nak a kalap-ja
Mari.DAT the hat-Poss.3sG
'Mari's hat'

Szabolcsi $(1984,1994)$ has convincingly argued for Hungarian that the nominative and the dative possessor occupy different structural positions in the DP. There are two types of evidence for this conclusion. (i) Linear order: the determiner $a(z)$ obligatorily follows the dative possessor but precedes the nominative possessor, cf. (27). (ii) Extraction asymmetries: only the dative possessor can be extracted from the DP, as shown in (28) for topicalization. Furthermore, wh-possessors must be dative and precede the determiner.

(28) Possessor extraction in Hungarian (Szabolcsi 1984):
a. Mari-nak nem ismert-em [ $\mathrm{t}^{\prime} \mathrm{t}$ növér-é-t] Mari-DAT not knew-1SG sister-Poss.3sG-ACC
'I never knew any sister of Mari.'
b. *Mari nem ismert-em [ $\mathrm{t}^{\prime} \mathrm{t}$ növér-é-t]
Mari.NOM not knew-1sg sister-Poss.3sG-ACC
'I never knew any sister of Mari.'

Szabolcsi (1994) takes this as evidence that the dative possessor is in a derived position, viz. SpecD. The possessor optionally moves to this position from a lower position that is associated with nominative case.

The question that arises is whether there is also evidence for two different positions of genitive and ablative possessors in Udmurt. This is not the case. First of all, linear order is not a viable test for Udmurt: there is no element like the Hungarian determiner relative to which the two possessors align differently. Furthermore, the extraction test does not suggest that the genitive and the 
ablative possessor occupy different structural positions: in contrast to Hungarian, the possessor can always be extracted, regardless of its case value. This is illustrated in (29) for extraposition and in (30) for topicalization; (30a) and (30c) contain the baseline sentence and (30b) and (30d) illustrate extraction.

(29) Extraposition of the genitive and ablative possessor in Udmurt (Vilkuna 1997: 224):

a. man'eryz sytše pereš Mikta-len manner.3sg such old Mikta-GEN 'Such is old Mikta's style.'
b. valze jusky so-leš
horse.ACc.3sG unharness.IMP.2sG s/he.ABL 'Unharness his horse!'

Poss with gen

Poss with $a b l$

(30) Topicalization of the genitive and ablative possessor:

a. Mon Masha-leš apaj-z-e noku no öj 1SG Masha-ABL sister-3SG-ACC never NEG.PST.1SG yet pumital'l'a

meet

'I never met Masha's sister.'

b. Masha-leš nokuno öj na pumital'l'a apaj-z-e Masha-ABL never NEG.PST.1SG yet met sister-3sG-ACC Lit: 'Masha's I never met sister.'

Poss with abl

c. Masha-len puny-jez zhug-em-yn val Masha-GEN dog-3SG beat-PARTC-INES AUX.PST.SG 'Masha's dog was beaten.'

d. Masha-len body-jen puny-jez zhug-em-yn val Masha-GEN club-INSTR dog-3SG beat-PARTC-INES AUX.PST.SG Lit: 'Masha's was dog beaten with a club.'

Poss with gen

Furthermore, wh-possessors can bear any of the two possessor cases, in contrast to Hungarian.

(31) Wh-possessors in Udmurt:

a. Kin-leš apaj-z-e jarat-is'ko-d who-ABL sister-3SG-ACC love-PRES.2SG 'Whose sister do you love?'

wh-Poss with abl

b. Kin-len apaj-ez Petyr-ez jarat-e who-Gen sister-3Sg Peter-ACC love-PRES.3SG 'Whose sister loves Peter?'

wh-Poss with gen 
To conclude, we do not have any evidence from extraction that genitive and ablative possessors in Udmurt occupy different structural positions in the DP. Thus, the null hypothesis that there is no possessor movement in Udmurt can be maintained.

Another analysis that comes to mind when looking at the case split in Udmurt is a possessor raising analysis. In some languages, possessors seem to be dependents of the verb instead of the possessum noun (external possession, see König and Haspelmath 1998 and Deal 2013a for an overview). External possessors are often taken to be moved from a DP-internal position into the vP domain; they receive an external case in this domain, i.e., a case that is not assigned to the possessor DP-internally (see e.g. Munro 1984; Allen et al. 1990; Landau 1999; Kishimoto 2013 and references cited therein). Hence, it is argued that the different structural positions (DP-internal vs. DP-external) are responsible for the case split. A recent proposal along these lines has been put forward in Deal (2013b) for Nez Perce. In this language, the possessor usually bears genitive, but if the possessum is the direct object, it bears the objective case (the case assigned to the internal argument of a transitive verb). Hence, there is a case split in Nez Perce that, at first sight, seems to be conditioned by the same factor as the split in Udmurt (but see Section 2.1 for refinements of the generalization in Udmurt). Deal (2013b) argues for Nez Perce that a possessor of an NP that is the direct object of a verb obligatorily undergoes movement out of the DP into a non-thematic A-position in the vP where it is assigned the objective case.

Evidence for raising comes from the observation that a possessor sometimes behaves like a dependent of the verb with respect to the following tests (see Stump and Yadav 1988 for an overview): (i) the raised possessor triggers agreement on the verb; the possessum ceases to do so. (ii) The raised possessor bears the prototypical case of a core argument; the possessum ceases to bear this case. (iii) If a language exhibits agreement between the possessor and the possessum, a raised possessor ceases to trigger agreement on the possessum. (iv) A raised possessor of the direct object can be bound by the subject. (v) A raised possessor can be freely separated from the possessum. (vi) The raised possessor of the direct object of a transitive verb can become the subject of the corresponding passivized verb. DP-internal possessors do not have these properties.

Concerning Udmurt, test (i) is not applicable since Udmurt does not have object agreement. With respect to test (ii), the result is negative: the exceptional possessor case (ablative) is not identical to the prototypical internal argument case, which is accusative. Furthermore, the possessum continues to bear accusative if the possessor has the ablative (cf. e.g. (1b)). As is also evident in (1b) and a number of other examples in this paper, agreement between the ablative possessor and the possessum is not suppressed. Thus, test (iii) does not provide 
evidence for possessor raising either. Turning to test (iv), it can be shown that the genitive and the ablative possessor in Udmurt do not differ in their binding domains:
a. Petyr as-lešt-yz puny-z-e jarat-e
Peter himself-ABL-3sg dog-3SG-ACC love-PRS.3SG
'Peter loves his own dog (not yours).'
b. Petyr as-la-z suzer-ez-ly l'uket-e
Peter himself-GEN-3SG sister-3SG-DAT bother-PRS.3SG
'Peter bothers his own sister (not yours).'

Possessive pronouns can be replaced by reflexives in contrastive or emphatic contexts in Udmurt. (32) shows that, independently of its case, the reflexive possessor of the direct object can be bound by the subject Peter. Thus, there is no evidence that the genitive and the ablative possessor belong to different binding domains. Again, this leads to the conclusion that there is no possessor raising in Udmurt.

With respect to test (v) we have already shown in (29), (30) and (31) that there are no extraction asymmetries in Udmurt between genitive and ablative possessors. We therefore conclude that there is no (obligatory) possessor raising of ablative possessors out of the DP either. ${ }^{22}$

In sum, there is no evidence for raising of the ablative possessor, neither to a DP-internal nor to a DP-external position. It behaves like the genitive possessor for all the relevant tests. The case split on Udmurt possessors must thus have a different source than the well-known cases of possessor case splits in the literature. Because of the absence of evidence for possessor raising, the present approach assumes that the possessor always stays in its base position SpecD and can be assigned case by an external head in this position - an idea originally proposed in the ECM-like accounts to possessor case splits by Massam (1985) and Baker (1988). Hence, Udmurt fills the gap in the typology of external possession proposed in Deal (2013a); the analysis can be described as a modern version of the "classical possessor government analysis".

Finally, it should be mentioned - as pointed out to us by Amy Rose Deal that the general idea of the analysis in Section 3 (that is, syntactic case stacking plus morphological fusion) can be maintained even if there was possessor raising. The reason is that possessor raising alone does not answer the question as to

22 As for test (vi), we do not have the relevant data, but according to our informant it seems to be impossible to make the possessor of a VP-internal DP to the subject under passivization, regardless of the case the possessor bears. Hence, genitive and ablative possessor pattern alike with respect to passivization, too. 
why we find the marked ablative case on the possessor instead of the standard accusative object case as in other possessor raising languages. The present analysis provides an answer to this question, independently of whether accusative is assigned to the possessor in situ (ECM-analysis) or in the vP-domain (raising analysis). ${ }^{23}$

\section{Cross-linguistic variation}

In the analysis in Section 3, it is assumed that Udmurt exhibits syntactic case stacking even though it does not exhibit overt case stacking like Huallaga Quechua in (18) does. Thus, we take syntactic case stacking - in the DP as well as in the clause - to be a widespread phenomenon that is, however, sometimes disguised by the way morphology realizes stacked abstract cases. In fact, a number of other phenomena in the DP have been treated as case stacking as well under the term Suffixaufnahme, which is the traditional label for case stacking on possessors (cf. Plank 1995 for an overview). The present analysis predicts a certain range of variation between languages along the following two parameters: (i) Restrictions on the number of cases that can stack (syntactically or morphologically) and (ii) the existence of morphological case stacking. We will show that examples for all these language types exist and that, consequently, the pattern in Udmurt presents just one of various possible realization strategies. We take this state of affairs as indirect evidence for the case stacking analysis of the Udmurt case split.

Parameter (i) is about restrictions on the number of cases that can stack:

(33) Parameter (i): number of cases that can stack

a. Number of cases limited:

(i) limited to one:

no case stacking

(ii) limited to two:

e.g. Kanyara and Mantharta languages.

(iii) limited to three

b. Number of cases unlimited: e.g. Martuthunira in (34).

23 It should be noted that there is in principle an alternative analysis according to which the ablative on the possessor is directly governed by the verb (for an example of a verb governing the ablative, see (14f)). This alternative cannot be maintained because the ablative on the possessor only occurs with verbs that assign accusative and never with verbs that assign ablative (see e.g. (8)); hence, the ablative on the possessor cannot simply be assigned by $\mathrm{V}$. 
Setting (33a-i) is trivial: if there is only a single case slot in the syntax in a language L, L does not have syntactic case stacking and hence, there can be no overt case stacking. On the other end of the continuum are languages in which the number of cases that can stack is unlimited. Martuthunira (Pama-Nyungan, Corbett 2006: 135) is an example of such a language, cf. (34).

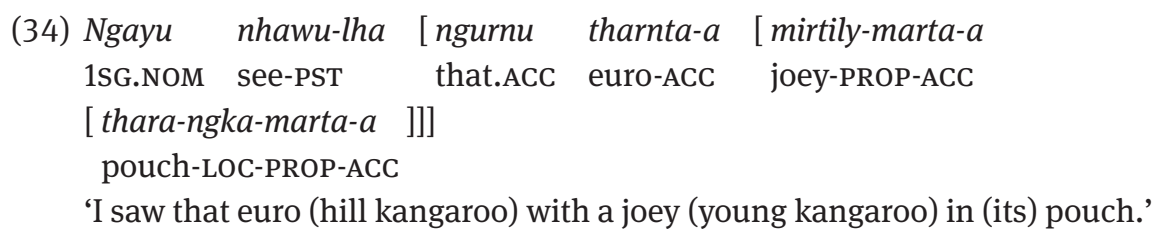

We assume that Udmurt represents an instance of the setting in (33a-ii). It allows for case stacking in the syntax but only in a very limited way: the number of cases that can stack is restricted to two (see footnote 14 for reasons why this is necessary). One might argue that this restriction is a stipulation, but apart from the fact that it makes correct predictions about the distribution of the ablative marker in structures with recursive possessors, it can be justified by the following observation: there are languages with overt case stacking that also have restrictions on the number of cases that can stack. In Kanyara and Mantharta languages (West Australia, Austin 1995), for example, the number of case markers that can stack overtly is limited to two. Hence, language-specific restrictions on the number of case slots seem to be unavoidable anyway (see example (i) in footnote 11).

In what follows, we concentrate on languages that allow for syntactic case stacking. The question is whether such languages can stack cases overtly, this is parameter (ii) on the morphological realization of stacked abstract case values (see Corbett 1995; Moravcsik 1995 for a similar though not identical typology of case stacking in the DP):

(35) Parameter (ii) on the realization of abstract case values:

a. Realization of all cases: overt case stacking; e.g. Huallaga Quechua

b. Realization of only one case:

(i) Case attraction: the case value that is assigned last is realized; e.g. Rithangu.

(ii) Case maintenance: the case that is assigned first to an element is realized, e.g. German.

(iii) Matching: Both case values are realized by a single marker, but this is only possible if the marker is syncretic for the two abstract cases; e.g. Polish. 
(iv) Allomorphy: a portmanteau morpheme realizes all abstract cases at once; e.g. Udmurt, Beztha (and other Daghestanian languages).

(v) Phonological repair (haplology effect): Phonologically identical case markers are not tolerated; e.g. Jiwarli, Old Georgian, Dyirbal.

If each of the abstract case values is realized by an overt case marker, a language is said to have overt case stacking, see the strategy in (35a). Huallaga Quechua (see (18)) is such a language. If, however, a language does not allow for the realization of more than one case marker, it can choose from among five different strategies to fulfill the morphological restriction to a single case marker.

The first strategy (cf. (35b-i)) is case attraction and is well attested in relative clauses: it is only the case value that is assigned last to an element that is morphologically realized. But this pattern is also found in the DP, e.g. in Rithangu (Pama-Nyungan, Schweiger 1995: 354f.; see also Pesetsky 2014 on this strategy in the Russian DP). The genitive case morpheme of the possessor is replaced by the case of the head noun if the latter is ablative, locative, allative or pergressive. If the head noun bears a different case, only the genitive is realized on the possessor, cf. the data in (36).

(36) Rithangu, case attraction in the DP:
a. $\underline{n u-\eta u}$ dawal
2SG-GEN country.NOM
'your country'
b. wa:n-i+nu+ra nui-kala-li? dawal-li?
go-FUT+now+1SG 2SG-LIG-ALL country-ALL
'I will now go to your country.'

head=allative

Another possible strategy of languages that have syntactic but not overt case stacking is what we call case maintenance in (35b-ii). It is the reverse of case attraction in that it is the case value assigned first to an element that is morphologically realized. The cases that are assigned later are ignored for morphological realization. Any language without overt stacking that does not apply any of the other strategies (attraction, matching, allomorphy) can be described in this way, e.g. German. Note that an ambiguity arises: it cannot be detected on the surface that these languages have syntactic case stacking at all. All of these languages could also be described as not having syntactic case stacking in the first place, i.e., only a single case value can be assigned to an element.

The third strategy in (35b-iii) is matching: a single case marker realizes the stacked abstract cases. But this marker needs to fulfill the requirement that it has to be syncretic for the abstract stacked case values; otherwise, the output 
is ungrammatical. We did not find an example of matching on possessors but this pattern is common in the clause, e.g. for across-the-board-movement of wh-phrases (under the assumption that the single overt wh-phrase is merged in multiple positions, see e.g. Citko 2005). ${ }^{24}$

(35b-i) and (35b-ii) are frequently discussed strategies in the literature. What we have proposed in this paper is that there is another strategy that we call the allomorphy strategy, cf. (35b-iv): the stacked cases are realized by a marker $M$ that does not correspond to any of the morphemes that would realize each of the stacked abstract cases alone. Rather, it seems to be the case that the marker $\mathrm{M}$ is a kind of portmanteau morpheme that realizes all stacked cases at once (cf. Moravcsik 1995: 462 for the term portmanteau in this context). This is the situation we find in Udmurt: if abstract genitive and accusative case stack, a morpheme shows up that neither corresponds to the genitive nor to the accusative VI, but another marker which, in Udmurt, is identical to the marker of the abstract ablative. Indeed, the Udmurt pattern has been described as a special kind of case stacking in the typological literature (cf. Corbett 1995; Kibrik 1995; Moravcsik 1995).

Furthermore, there are languages that do not have a morphological restriction on the number of cases that can be realized, but rather a phonological restriction (cf. strategy (35b-v)). In some languages, case stacking is possible, but if two stacked case morphemes on the possessor are phonologically identical, one of them is deleted. This is the case in Jiwarli and Dyirbal (Pama-Nyungan, Austin 1995; Schweiger 1995), and Old Georgian (Kartvelian, Boeder 1995); see Dench and Evans 1988 for further examples.

To summarize, linguistic variation reduces to (i) whether there are restrictions on the number of cases that can stack (syntactically or morphologically) and (ii) the morphological realization of syntactic case stacking. Given these parameters, Udmurt exhibits just one of the expected repair strategies that apply when a language has syntactic case stacking but no morphological stacking, i.e., if it has only a single morphological case slot. The present analysis is a formal implementation of the intuition found in the typological literature that the Udmurt pattern (the allomorphy strategy) is indeed a special case of case stacking in which the two cases are expressed by a single lexical item. This view seems to be

24 Beside ATB-movement constructions, matching is also found with other phenomena such as parasitic gaps (cf. Levine et al. 2001; Kathol 2001) and free relative clauses (cf. Bresnan and Grimshaw 1978; Groos and Riemsdijk 1981). As pointed out by a reviewer, another possible instance of the matching strategy concerning raising-to-object phenomena in Norwegian is given in Béjar and Massam (1999). 
on the right track given that in all the languages with the Udmurt pattern that we know of (in particular Daghestanian languages) the case split depends on the case assigned by an external head.

\section{Conclusion}

In this paper, we examined the case split in Udmurt: possessors bear either a genitive or an ablative case suffix. These cases are in complementary distribution. Traditionally, the case split in Udmurt is described as being driven by the GF of the XP containing the possessor, defined by its position in the syntactic structure. The choice of the possessor case in the DP thus seems to require look-ahead. We have shown that there is no evidence that the split in Udmurt is based on different structural positions of the possessor; rather, it is determined by the case value that the DP containing the possessor is assigned. This new generalization facilitates a local reanalysis in terms of case stacking: the possessor is always assigned genitive in the DP and it may in addition be assigned another structural case from the external head which selects the DP. Since there is only a single morphological slot for a case marker in Udmurt, the two case features have to fuse into a single feature structure in the postsyntactic morphological component. Only in case of a combination of abstract genitive and accusative does a feature structure arise which is realized by the default semantic VI, the ablative exponent. There is thus never abstract ablative case on the possessor. This analysis does neither require look-ahead nor counter-cyclic case assignment at any point of the derivation.

Independent motivation for the case stacking analysis comes from crosslinguistic variation: Udmurt simply uses one of the various expected strategies to resolve the conflict that arises when several abstract cases 'compete' for a single morphological case slot. Some languages realize both cases (overt case stacking), some only one of them and others, like Udmurt, fuse the abstract cases. The resulting case feature is realized by an exponent that may be different from the exponents that would have realized each of the two original case values, thus creating the illusion that the possessor is sometimes assigned genitive and sometimes ablative in the syntax, although it is never assigned abstract ablative.

Acknowledgments: For valuable comments and discussion we would like to thank the participants of the syntax colloquium at the University of Leipzig as well as the audiences at BCGL 7 (Brussels, December 2012), ConSOLE XXI (Potsdam, January 2013) and GLOW 36 (Lund, April 2013). In particular, we are grateful to Jeroen van Craenenbroeck, Anders Holmberg, Norvin Richards, Henk van Riemsdijk, Anne Vainikka and two reviewers for their suggestions. Furthermore, we would like 
to thank Ekaterina Georgieva for putting us in contact with Svetlana Edygarova, as well as Christian Pischlöger for help with the interpretation of the Finnish sources and András Bárány for help with the Hungarian sources. This research is supported by DFG-grant MU 144/8-1 ("Local modeling of non-local dependencies in syntax"): http://www.uni-leipzig.de/ lomo.

\section{References}

Alexiadou, Artemis \& Elena Anagnostopoulou. 1998. Parametrizing AGR: Word Order, V-Movement and EPP-Checking. Natural Language and Linguistic Theory 16, 491-539.

Allen, Barbara, Donald Frantz, Donna Gardiner \& David Perlmutter. 1990. Verb agreement, possessor ascension, and multistratal representation in Southern Tiwa. In Paul Postal \& Brian Joseph (eds.), Studies in relational grammar 3, 321-382. Chicago: University of Chicago Press.

Assmann, Anke. 2014. Case Stacking in Nanosyntax. Ms., Universität Leipzig.

Austin, Peter. 1995. Double Case Marking in Kanyara and Mantharta Languages, Western Australia. In Frans Plank (ed.), Double Case: Agreement by Suffixaufnahme, 363-379. New York: Oxford University Press.

Babby, Leonard. 1984. Case Conflicts and Their Resolutions: A Contribution to EST Case Theory. Cornell Wokring Papers in Linguistics 6, 1-21.

Babby, Leonard. 1990. The syntax of surface case. Cornell Working Papers in Linguistics 1, 1-32.

Baker, Mark C. 1988. Incorporation: A theory of grammatical function changing. Chicago: University of Chicago Press.

Béjar, Susana \& Diane Massam. 1999. Multiple Case Checking. Syntax 2, 65-79.

Bierwisch, Manfred. 1967. Syntactic Features in Morphology: General Problems of So-Called Pronominal Inflection in German. In To Honour Roman Jakobson, 239-270. The Hague: Mouton.

Bjorkman, Bronwyn. to appear. The Syntax of Syncretism. North East Linguistic Society (NELS) 40.

Bobaljik, Jonathan. 2002. Syncretism without Paradigms: Remarks on Williams 1981, 1994. In Geert Booij \& Jaap van Marle (eds.), Yearbook of Morphology 2001, 53-85. Dordrecht: Kluwer.

Boeder, Winfried. 1995. Suffixaufnahme in Kartvelian. In Frans Plank (ed.), Double Case: Agreement by Suffixaufnahme, 151-215. New York: Oxford University Press.

Bonet, Eulália. 1991. Morphology after syntax. Cambridge, MA.: MIT dissertation.

Bresnan, Joan \& Jane Grimshaw. 1978. The Syntax of Free Relatives in English. Linguistic Inquiry 9, 331-391.

Caha, Pavel. 2009. The nanosyntax of case. Tromsø: CASTL dissertation.

Chomsky, Noam. 1995. The Minimalist Program. Cambridge, MA.: MIT Press.

Chomsky, Noam. 2001. Derivation by Phase. In Michael Kenstowicz (ed.), Ken Hale. A Life in Language, 1-52. Cambridge, MA.: MIT Press.

Chvany, Catherine. 1986. Jakobson's Fourth and Fifth Dimensions: On Reconciling the Cube Model with Two-Dimensional Matrices for Case Forms. In Richard Brecht \& James Levine (eds.), Case in Slavic, 107-129. Columbus, Ohio: Slavica. 
Citko, Barbara. 2005. On the Nature of Merge: External Merge, Internal Merge, and Parallel Merge. Linguistic Inquiry 36, 475-496.

Corbett, Greville G. 1995. Slavonic's Closest Approach to Suffixaufnahme: The Possessive Adjective. In Frans Plank (ed.), Double Case: Agreement by Suffixaufnahme, 265-282. New York: Oxford University Press.

Corbett, Greville G. 2006. Agreement. Cambridge: Cambridge University Press.

Csúcs, Sándor. 1988. Udmurt. In Daniel Abondolo (ed.), The Uralic Languages, 276-304. London: Routledge.

Deal, Amy Rose. 2013a. External Possession and Possessor Raising. To appear in Martin Everaert \& Henk van Riemsdijk, eds, The Companion to Syntax, 2nd edn. Wiley-Blackwell. Available at LingBuzz: lingbuzz/001799.

Deal, Amy Rose. 2013b. Possessor Raising. Linguistic Inquiry 44, 391-432.

Dench, Alan \& Nicholas Evans. 1988. Multiple Case Marking in Australian Languages. Australian Journal of Linguistics 8, 1-47.

Diesing, Molly. 1992. Indefinites. Cambridge, MA.: MIT Press.

Edygarova, Svetlana. 2009. Attributive Possession in Udmurt Language. Linguistica Uralica XLV, 101-118.

Edygarova, Svetlana. 2010. Kategoria possessivnosti v Udmurtskom jazyke [The possessive category in the Udmurt language]. Estonia: University of Tartu dissertation. Dissertationes Philologiae Uralicae Universitatis Tartuensis 7.

Erlewine, Michael Yoshitaka. 2013. Dissociating the syntax and morphological realization of Kaqchikel Agent Focus. MIT Working Papers on Endangered and Less Familiar Languages 8, 25-50.

Frampton, John. 2002. Syncretism, Impoverishment, and the Structure of Person Features. Chicago Linguistics Society Meeting (CLS) 38, 207-222.

Frampton, John \& Sam Gutman. 2006. How Sentences Grow in the Mind: Agreement and Selection in Efficient Minimalist Syntax. In Cedric Boeckx (ed.), Agreement Systems, 121-157. Amsterdam: Benjamins. Linguistik aktuell 92.

Franks, Steven. 1995. Parameters of Slavic morphosyntax. Oxford University Press: Oxford Studies in Comparative Syntax.

Grewendorf, Günther. 1989. Ergativity in German. Dordrecht: Foris.

Groos, Anneke \& Henk van Riemsdijk. 1981. Matching Effects with Free Relatives:

A Parameter of Core Grammar. Generative Linguistics in the Old World (GLOW) 2, 171-216.

Halle, Morris. 1997. Distributed Morphology: Impoverishment and Fission. MIT Working Papers in Linguistics 20, 425-449.

Halle, Morris \& Alec Marantz. 1993. Distributed Morphology and the Pieces of Inflection. In Ken Hale \& Samuel Jay Keyser (eds.), The View from Building 20, 111-176. Cambridge, MA.: MIT Press.

Halle, Morris \& Alec Marantz. 1994. Some Key Features of Distributed Morphology. MIT Working Papers in Linguistics 21, 275-288.

Halle, Morris \& Bert Vaux. 1997. Theoretical Aspects of Indo-European Nominal Morphology: The Nominal Declensions of Latin and Armenian. In Jay Jasanoff, Craig Melchert \& Lisi Oliver (eds.), Mir Curad: Studies in Honor of Calvert Watkins, 223-240. Innsbruck: Institut für Sprachwissenschaft, Universität Innsbruck.

Harley, Heidi \& Elisabeth Ritter. 2002. Person and Number in Pronouns: A Feature-Geometric Analysis. Language 78, 482-526. 
Hiraiwa, Ken. 2001. Multiple Agree and the Defective Intervention Constraint in Japanese. UCLA Working Papers in Linguistics 40, 67-80.

Hole, Daniel. 2008. Dativ, Bindung und Diathese. Habilitationsschrift, Humboldt-Universität zu Berlin.

Kathol, Andreas. 2001. Nonexistence of Parasitic Gaps in German. In Peter Culicover \& Paul Postal (eds.), Parasitic Gaps, 315-338. Cambridge, MA.: MIT Press.

Kel'makov, Valentin K. \& Sara Hännikäinen. 1999. Udmurtin kielioppia ja harjoituksia [Udmurt grammar and exercises]. Helsinki: Suomalais-Ugrilainen Seura.

Kibrik, Aleksandr E. 1995. Direct-Oblique Agreement of Attributes in Daghetanian. In Frans Plank (ed.), Double Case: Agreement by Suffixaufnahme, 216-229. New York: Oxford University Press.

Kiparsky, Paul. 2001. Structural Case in Finnish. Lingua 111, 315-376.

Kishimoto, Hideki. 2013. Covert possessor raising in Japanese. Natural Language and Linguistic Theory 31, 161-205.

König, Ekkehard \& Martin Haspelmath. 1998. Les constructions à possesseur externe dans les langues d'Europe. In Jack Feuillet (ed.), Actance et valence dans les langues de l'Europe, 525-606. Berlin: Mouton de Gruyter.

Koptjevskaja-Tamm, Maria. 2003. Possessive Noun Phrases in the Languages of Europe. In Frans Plank (ed.), Empirical Approaches to Language Typology, 621-722. Berlin/New York: de Gruyter.

Landau, Idan. 1999. Possessor raising and the structure of VP. Lingua 107, 1-37.

Legate, Julie Anne. 2008. Morphological and Abstract Case. Linguistic Inquiry 39, 55-101.

Levine, Robert D., Thomas E. Hukari \& Michael Calcagno. 2001. Parasitic Gaps in English: Some Overlooked Cases and Their Theoretical Implications. In Peter D. Culicover \& Paul M. Postal (eds.), Parasitic Gaps, 181-222. Cambridge, MA.: MIT Press.

Massam, Diane. 1985. Case Theory and the Projection Principle. Cambridge, MA.: MIT dissertation.

Matushansky, Ora. 2008. Predication: A Case Study. In F. Marušic \& R. Žaucer (eds.), Studies in Formal Slavic Linguistics. Contributions from Formal Description of Slavic Languages 6.5, 213-239. Frankfurt am Main: Peter Lang.

McCreight, Katherine. 1988. Multiple case assignments. Cambridge, MA.: MIT dissertation.

Merchant, Jason. 2006. Polyvalent case, geometric hierarchies, and split ergativity. Chicago Linguistics Society (CLS) 42, 47-67.

Moravcsik, Edith A. 1995. Summing up Suffixaufnahme. In Frans Plank (ed.), Double Case: Agreement by Suffixaufnahme, 451-484. New York: Oxford University Press.

Müller, Gereon. 2004. A Distributed Morphology Approach to Syncretism in Russian Noun Inflection. Formal Approaches to Slavic Linguistics (FASL) 12, 353-373.

Munro, Pamela. 1984. The syntactic status of object possessor raising in Western Muskogean. Berkeley Linguistics Society (BLS) 10, 634-639.

Nevins, Andrew. 2003. Do Person/Number Syncretisms Refer to Negative Values?. Paper presented at the LSA meeting 2003, lingbuzz/000104.

Nikolaeva, Irina. 2002. The Hungarian External Possessor in a European Perspective. In Cornelius Hasselblatt \& Rogier Blokland (eds.), Finno-Ugrians and Indo-Europeans: Linguistic and literary contacts, 272-285. Maastricht: Shaker.

Nordlinger, Rachel. 1998. Constructive case: Evidence from Australian languages. Stanford: CSLI. 
Noyer, Rolf. 1992. Features, positions and affixes in autonomous morphological structure. Cambridge, MA.: MIT dissertation.

Pesetsky, David. 2014. Russian case morphology and the syntactic categories. LI Monograph 66. Cambridge, MA.: MIT Press.

Plank, Frans. 1995. (Re-)Introducing Suffixaufnahme. In Frans Plank (ed.), Double Case: Agreement by Suffixaufnahme, 3-110. New York: Oxford University Press.

Pylkkänen, Liina. 2002. Introducing arguments. Cambridge, MA.: MIT dissertation.

Řezáč, Milan. 2004. Elements of cyclic syntax: Agree and Merge. Toronto: University of Toronto dissertation.

Řezáč, Milan. 2008. Phi-Agree and theta-related Case. In Daniel Harbour, David Adger \& Susana Béjar (eds.), Phi theory, 83-129. Oxford: Oxford University Press.

Richards, Marc. 2008. Quirky Expletives. In Roberta d'Alessandro, Gunnar H. Hrafnbjargarson \& Susann S. Fischer (eds.), Agreement Restrictions, 181-213. Berlin: Mouton de Gruyter.

Richards, Norvin. 2013. Lardil "Case Stacking” and the Timing of Case Assignment. Syntax 16, 42-76.

Schoorlemmer, Erik. 2009. Agreement, dominance and doubling. The morphosyntax of DP. Utrecht: LOT.

Schweiger, Fritz. 1995. Suffixaufnahme and Related Case Marking Patterns in Australian Languages. In Frans Plank (ed.), Double Case: Agreement by Suffixaufnahme, 339-362. New York: Oxford University Press.

Stump, Gregory \& Ramawatar Yadav. 1988. Maithili Verb Agreement and the Control Agreement Principle. Chicago Linguistic Society (CLS) 24, 304-321.

Szabolcsi, Anna. 1984. The Possessor that Ran Away from Home. The Linguistic Review 3, 89-102.

Szabolcsi, Anna. 1994. The Noun Phrase. In Ferenc Kiefer (ed.), Syntax and Semantics, vol 27: The Structure of Hungarian, 179-274. San Diego: Academic Press.

Vainikka, Anne. 1993. Three structural cases in Finnish. In Anders Holmberg \& Urpo Nikane (eds.), Case and Other Functional Categories in Finnish Syntax, 129-159. Berlin: Mouton de Gruyter.

Vainikka, Anne \& Pauli Brattico. 2014. The Finnish Accusative: Long Distance Case Assignment Under Agreement. Linguistics 52, 73-124.

Vilkuna, Maria. 1997. Word Order in European Uralic. In Anna Siewierska (ed.), Constituent Order in the Languages of Europe, 173-233. Berlin: Mouton de Gruyter.

Weisser, Philipp. 2006. A Distributed Morphology analysis of Croation noun inflection. In Gereon Müller \& Jochen Trommer (eds.), Subanalysis in Argument Encoding in Distributed Morphology. Linguistische Arbeits Berichte 84, 131-142.

Wiese, Bernd. 2001. Zur lateinischen Deklination: Die Form-Funktions-Beziehung. Ms., IDS Mannheim.

Winkler, Eberhard. 2001. Udmurt. Languages of the world: Materials, Vol. 212. München: LINCOM Europa.

Wunderlich, Dieter \& Renate Lakämper. 2001. On the interaction of structural and semantic case. Lingua 111, 277-418.

Ylikoski, Jussi. 2011. A survey of the origins of directional case suffixes in European Uralic. Amsterdam: John Benjamins.

Zwicky, Arnold. 1977. Hierarchies of Person. Chicago Linguistic Society (CLS) 13, 714-733. 